\title{
A Single-Center 10-Year Experience with Pasireotide in Cushing's Disease: Patients' Characteristics and Outcome
}

\author{
Authors \\ L. Trementino $^{1 *}$, G. Michetti ${ }^{1}$, A. Angeletti ${ }^{1}$, G. Marcelli ${ }^{1}$, C. Concettoni ${ }^{1}$, C. Cardinaletti ${ }^{1}$, B. Polenta ${ }^{1}$, \\ M. Boscaro ${ }^{2}$, G. Arnaldi ${ }^{1}$ \\ Affiliations \\ ${ }^{1}$ Division of Endocrinology, AOU Ospedali Riuniti, Ancona, Italy \\ ${ }^{2}$ Department of Medicine DIMED, University-Hospital of Padua, Endocrinology Unit, Padua, Italy
}

\author{
Key words \\ endogenous hypercorti- \\ solism \\ pituitary \\ - somatostatin analogue \\ - medical treatment \\ - long-term
}

received $\quad 03.09 .2015$

accepted 13.01.2016

Bibliography

DOI http://dx.doi.org/

10.1055/s-0042-101347

Horm Metab Res 2016;

48: 290-298

(c) Georg Thieme Verlag KG

Stuttgart · New York

ISSN 0018-5043

Correspondence

\section{G. Arnaldi, MD}

Division of Endocrinology AOU Ospedali Riuniti

Via Conca 71

60020 Torrette di Ancona (AN) Italy

Tel.: + 39/71/5964 419

Fax: + 39/71/5964 419

gioarnaldi@gmail.com

\section{License terms}

\section{Abstract \\ $\nabla$}

Pasireotide is the first pituitary-directed drug approved for treating patients with Cushing's disease (CD). Our 10-year experience with pasireotide in $C D$ is reported here. Twenty patients with de novo, persistent, or recurrent $C D$ after pituitary surgery were treated with pasireotide from December 2003 to December 2014. Twelve patients were treated with pasireotide in randomized trials and 8 patients with pasireotide sc (Signifor $^{\circledR}$; Novartis AG, Basel, Switzerland) in clinical practice. The mean treatment duration was 20.5 months (median 9 months; range, 3-72 months). Urinary free cortisol (UFC) levels mean percentage change $( \pm S D)$ at last follow-up was $-40.4 \%$ ( \pm 35.1 ; range, $2-92 \%$; median reduction $33.3 \%$ ) with a normalization rate of $50 \%$ $(10 / 20)$. Ten patients achieved sustained normalized late night salivary cortisol (LNSC) levels during

\section{Introduction}

Cushing's disease (CD) is a rare and severe clinical disorder caused by an ACTH-secreting pituitary adenoma and characterized by chronic exposure to cortisol excess [1]. Pituitary surgery is the first-line therapy [2]; however, the longterm remission rate is lower and up to $20 \%$ of patients present recurrent disease $[3,4]$. Persistent hypercortisolism has been associated with impaired health-related quality of life and increased mortality, mainly due to cardiovascular complications [5-7].

Considering the benefit to risk ratio related to alternative treatments such as repeated pituitary surgery, bilateral adrenalectomy, and radiotherapy $[3,4]$, there is an absolute need for a longterm effective and safe medical therapy in

\footnotetext{
* Laura Trementino and Grazia Michetti have contributed
} equally to the present work treatment. LNSC normalization was associated with UFC normalization in 7/10 patients. Serum cortisol and plasma ACTH significantly decreased from baseline to last follow-up. Body weight decrease and blood pressure improvement during pasireotide treatment were independent from UFC response. Glucose profile worsening was observed in all patients except one. The frequency of diabetes mellitus increased from $40 \%$ $(8 / 20)$ at baseline to $85 \%(17 / 20)$ at last follow-up requiring initiation of medical treatment only in $44 \%$ of patients. Pasireotide treatment was associated with sustained biochemical and clinical benefit in about $60 \%$ of $C D$ patients. Glucose profile alteration is a frequent complication of pasireotide treatment; however, it seems to be easy to manage with diet and lifestyle intervention in almost half of the patients.

Supporting Information for this article is available online at http://www.thieme-connect.de/products

patients with $\mathrm{CD}$ and persistent/recurrent hypercortisolism.

Pasireotide is a multireceptor-targeted somatostatin analogue acting at pituitary level recently approved in both the EU and US for the treatment of adult patients with $\mathrm{CD}$ in whom surgery has failed or is declined. The Phase III study found that pasireotide treatment is effective in reducing biochemical markers as well as in improving signs and symptoms of hypercortisolism in about $30-50 \%$ of $C D$ patients with a safety profile similar to other somatostatin analogues with the exception of the increased risk of hyperglycemia $[8,9]$. The 2-year extended Phase II and Phase III studies confirmed these results and the longterm benefit achieved during pasireotide treatment $[10,11]$.

In this study, we report our 10-year experience with pasireotide in $\mathrm{CD}$ by reviewing and analyzing data about all the patients treated with pasireotide at our referral center and regularly 
followed up to 6 years. This is the first study that reports detailed data of patients treated with pasireotide both in randomized trials and in clinical practice. The aim of the present study is to evaluate the efficacy and safety of short, medium, and long-term treatment with pasireotide and furthermore to investigate possible predictive factors of response to treatment, as well as risk factors for hyperglycemia-related adverse events (AEs) development in these patients.

\section{Patients and Methods \\ $\nabla$ \\ Patients}

We retrospectively investigated 21 patients with de novo, persistent, or recurrent $C D$ after pituitary surgery referred to our center (Division of Endocrinology, AOU Ospedali Riuniti, Ancona, Italy) and treated with pasireotide from December 2003 to December 2014. The diagnosis of active CD was made on the basis of clinical features and laboratory assessments according to the consensus statement and clinical practice guidelines $[12,13]$. When appropriate inferior petrosal sinus sampling (IPSS) was performed to confirm the pituitary source of ACTH hypersecretion.

Twelve patients were treated with pasireotide in randomized trials: 6 patients were enrolled and treated with subcutaneous (sc) pasireotide in Phase II (core and extension study) CSOM230B2208 [10,14] and 6 patients were enrolled and treated with pasireotide sc in the Phase III study (core and extension study) CSOM230B2305 $[8,11]$. The remaining 8 patients were treated with pasireotide sc (Signifor ${ }^{\circledR}$; Novartis AG, Basel, Switzerland) in clinical practice.

The mean treatment duration with pasireotide was 20.5 months (median 9 months; range, 3-72 months). One patient was treated with pasireotide only for 15 days and thus he was excluded from data analysis.

Pasireotide sc was self-administered twice a day (at 09:00 and 21:00 h). The mean daily dose of pasireotide sc was $1320 \mu \mathrm{g}$ (range, 1200-1800 $\mu \mathrm{g}$ ) at the beginning of treatment as well as $1410 \mu \mathrm{g}$ at last follow-up (range, 600-2400 $\mu \mathrm{g}$ ).

For patients treated with pasireotide sc in randomized trials pasireotide dosage adjustment during follow-up was made according to protocol indication. In patients treated in clinical practice pasireotide dose increase or decrease was made on the basis of UFC levels, tolerance and clinical judgment. Clinical and biochemical assessments were scheduled according to protocol indication for patients enrolled in randomized trials and according to clinical practice in the remaining patients.

In patients treated with pasireotide in randomized trials, the same biochemical parameters required by protocol and evaluated centrally were collected in duplicate for local assessment.

The changes in clinical and biochemical parameters during pasireotide treatment were evaluated at month 3 and then at last follow-up.

Tumor volume was assessed by pituitary MRI every 6 months in patients treated with pasireotide in randomized trial (protocol indication) as well as in patients treated with pasireotide in clinical practice but with the evidence of an ACTH-secreting macroadenoma before starting pasireotide treatment. In the remaining patients, pituitary MRI was performed every 12 months according to clinical practice.

\section{Clinical evaluation}

Clinical examination included weight, height, body mass index (BMI), waist circumference, and arterial blood pressure. Arterial hypertension was defined as the presence of systolic blood pressure $(\mathrm{SBP}) \geq 140 \mathrm{mmHg}$, and/or diastolic blood pressure (DBP) $\geq 90 \mathrm{mmHg}$, and/or antihypertensive treatment [15].

Improvement in blood pressure during pasireotide treatment was determined if hypertensive patients passed to nonhypertensive values and/or if any antihypertensive treatment was modified (number of antihypertensive drugs reduced or reduced dosage) at the end of follow-up.

The improvement of body weight during pasireotide treatment was defined by a $>5 \%$ reduction between baseline values and last follow-up evaluation.

\section{Hormonal evaluation}

Hormonal evaluation included plasma ACTH, morning serum cortisol, late-night salivary cortisol (LNSC), and 24-houry urinary free cortisol (UFC) assessment. UFC levels were calculated as the mean value of at least 2 consecutive-day samples.

\section{Biochemical evaluation}

Biochemical assessment included glucose and lipid profile. The diagnosis of type 2 diabetes mellitus was made according to the criteria recently revised by the American Diabetes Association [16]. Patients were also considered diabetic if they were taking any hypoglycemic drug. At baseline, an oral glucose tolerance test (OGTT) was performed in all patients without a prior diagnosis of diabetes, not on therapy for the condition and with fasting plasma glucose (FPG) $<126 \mathrm{mg} / \mathrm{dl}$. Based on American Diabetes Association criteria [16] the diagnosis of prediabetes was defined by the presence of impaired fasting glucose (IFG) or impaired glucose tolerance (IGT). We defined the new-onset diabetes as the occurrence of diabetes after pasireotide (NODAP) treatment in previously nondiabetic or prediabetic patients following pasireotide treatment.

To identify potential risk factors for pasireotide-induced diabetes mellitus development the following parameters were considered: family history of diabetes, BMI, waist circumference and HOMA-IR. Insulin resistance was assessed by homeostasis model assessment (HOMA) by the following formula: HOMA-IR=(fasting glucose $(\mathrm{mmol} / \mathrm{l}) \times$ fasting insulin $(\mathrm{mU} / \mathrm{l}) / 22.5$ [17]

\section{Assays}

All biochemical assessments were performed in our Institute. Chemiluminescent immunometric assays were used to measure plasma ACTH (Immulite, DPC, Los Angeles, CA, USA) and serum cortisol (Advia Centaur; Bayer Diagnostics, Newbury, UK). Method sensitivity was $4.54 \mathrm{pg} / \mathrm{ml}$ for plasma ACTH and $0.4 \mathrm{mg} /$ $\mathrm{dl}$ for serum cortisol; intra-assay and interassay variation coefficients were 3.4 and $4.8 \%$ for plasma ACTH and 4.4 and $6.0 \%$ for serum cortisol, respectively. Normal ranges: $0-46 \mathrm{pg} / \mathrm{ml}$ for plasma ACTH and $5-23 \mu \mathrm{g} / \mathrm{dl}$ for morning serum cortisol (08:30h).

Considering the different assays used from 2004 to 2014 for UFC and LNSC measurements and consequently the different normal values, we expressed all the data as the ratio between the detected value and the upper normal limit (ULN) of each assay. Plasma glucose, glycated hemoglobin (HbA1c), insulin levels, total serum cholesterol, serum triglycerides, low-density lipoprotein (LDL), and high-density lipoprotein (HDL) were measured by standard procedures. 
Predictive factors of response to pasireotide treatment Looking to possible predictive factors of response to pasireotide in $\mathrm{CD}$ the following baseline parameters were investigated: age, sex, disease type (de novo, persistent, recurrent), disease severity (mild, moderate, severe), plasma ACTH, serum morning cortisol, and LNSC levels as well as ACTH response to CRH and/or desmopressin (DDAVP) stimulation test and/or serum cortisol levels after $1 \mathrm{mg}$ dexamethasone suppression test (1 mg DST). UFC, LNSC, plasma ACTH, and morning serum cortisol percentage changes in the first 3 months of treatment with pasireotide were also evaluated. Response to treatment was defined on the basis of UFC reduction/normalization and clinical improvement over time.

\section{Statistical analysis}

The Kolmogorov-Smirnov test was applied to verify the normal distribution of quantitative variables. Based on data distribution, comparison of continuous variables between the 2 groups was performed by the Student's $t$-test or the Mann-Whitney rank sum test. One-way ANOVA or Kruskal-Wallis ANOVA was used to compare variables between different groups and the Bonferroni test for post-hoc analysis. Categorical variables were analyzed by the $x^{2}$ test or Fisher's exact test if appropriate. Linear relationships between parameters were tested using the Pearson product-moment correlation coefficient ( $r$ ).

Logistic regression analysis was used to assess the association between response to pasireotide treatment (dependent variable) and age, sex, disease severity, disease type, duration of pasireotide treatment, baseline plasma ACTH, morning serum cortisol, LNSC, and UFC levels as well as hormonal response at month 3 (independent variables).

Receiver operating characteristic (ROC) curve analysis were used to evaluate the predictive value of the UFC and LNSC percentage reduction at month 3 for the response to treatment with pasireotide. ROC curves were generated by plotting the relationship of true positivity (sensitivity) and false positivity (1-specificity) at various cutoff points of the tests. Efficacy of pasireotide was evaluated using the intention-to-treat analysis last observation carried forward (LOCF). A p-value $<0.05$ was considered significant. All statistical analyses were performed using SPSS software version 22.0 (SPSS Inc., Chicago, IL, USA).

\section{Results \\ $\nabla$}

Baseline characteristics of the study population are reported in $\odot$ Table 1.

\section{Efficacy}

\section{Urinary free cortisol}

In the overall population, the mean percentage change $( \pm S D)$ at last follow-up was $-40.4 \%( \pm 35.1$; range, $2-92 \%$; median reduction $33.3 \%$ ) with a normalization rate of $50 \%(10 / 20)$.

Compared to baseline values the reduction in UFC levels was significant both at month 3 and at last follow-up $(p<0.05)$.

Among the $10 \mathrm{CD}$ patients that normalized UFC levels during pasireotide treatment, normalization occurred by months 1-3 in the majority of them $(8 / 10 ; 80 \%)$. The mean percentage reduction in UFC values at month 3 and at last follow-up according to disease severity at baseline (mild, moderate and severe) are shown in $\bullet$ Fig. 1.
Table 1 Baseline characteristics of the study population.

\begin{tabular}{|c|c|}
\hline Characteristics & All Patients $(n=20)$ \\
\hline \multicolumn{2}{|l|}{ Gender } \\
\hline Female & $17(85)$ \\
\hline Male & $3(15)$ \\
\hline \multicolumn{2}{|l|}{ Age, years } \\
\hline Mean \pm SD [range] & $49.7 \pm 11.2[32-71]$ \\
\hline \multicolumn{2}{|l|}{ Race } \\
\hline Caucasian & $20(100)$ \\
\hline \multicolumn{2}{|l|}{ Cushing's disease severity } \\
\hline Mild (UFC 1-1.9 × ULN) & $12(60)$ \\
\hline Moderate (UFC 2-5×ULN) & $5(25)$ \\
\hline Severe (UFC $>5 \times$ ULN) & $3(15)$ \\
\hline Serum cortisol > ULN & $8(40)$ \\
\hline Plasma ACTH $\geq$ ULN & $16(80)$ \\
\hline LNSC $\geq$ ULN & $18(94)$ \\
\hline \multicolumn{2}{|l|}{ Cushing's disease type } \\
\hline De novo & $10(50)$ \\
\hline Persistent & $6(30)$ \\
\hline Recurrent & $4(20)$ \\
\hline \multicolumn{2}{|c|}{ Previous treatment in persistent/recurrent } \\
\hline Surgery & $9(90)$ \\
\hline Medication & $5(50)$ \\
\hline Radiation therapy & $3(30)$ \\
\hline \multicolumn{2}{|l|}{ Pituitary imaging at diagnosis } \\
\hline Microadenoma (diameter $<10 \mathrm{~mm}$ ) & $11(55)$ \\
\hline Macroadenoma (diameter $\geq 10 \mathrm{~mm}$ ) & $3(15)$ \\
\hline No visible adenoma & $6(30)$ \\
\hline \multicolumn{2}{|l|}{ Treatment setting } \\
\hline Clinical practice & $8(40)$ \\
\hline Randomized trials & $12(60)$ \\
\hline
\end{tabular}

Data are expressed as number (percentage) unless otherwise specified

UFC: Urinary free cortisol; ULN: Upper normal limit; LNSC: Late night salivary cortisol

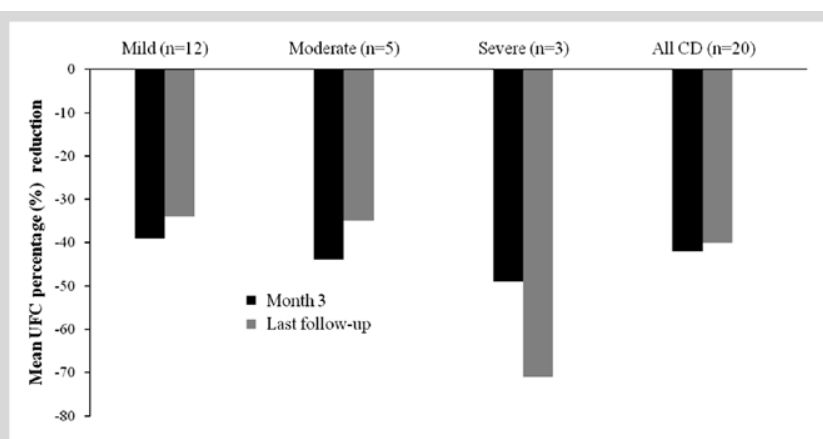

Fig. 1 Mean percentage reduction in UFC values from baseline to month 3 and last follow-up according to disease severity at baseline. (Mild = UFC 1-1.9 $\times$ ULN; Moderate $=$ UFC $2-5 \times$ ULN; Severe $=U F C>5 \times U L N)$.

Patients achieving normalized UFC levels during pasireotide treatment were older $(54.7 \pm 11.7$ vs. $44.8 \pm 8.5$ years; $p=0.046)$ and showed a significant mean percentage reduction at month 3 (54.6 \pm 21.1 vs. $31.2 \pm 20.3 \%$; $\mathrm{p}=0.025)$ than those who did not, while no significant differences were found in gender distribution, disease severity, disease type (de novo, persistent or recurrent), pituitary imaging (microadenoma, macroadenoma, or no visible adenoma) and pasireotide treatment duration.

When patients were evaluated according to treatment setting (clinical practice vs. randomized trials), patients treated with pasireotide in day-to-day clinical practice showed a trend towards higher rate of normalized UFC levels compared to those enrolled in randomized trials ( 75 vs. $33 \%$; $p=0.08$ ). 
All the patients treated with pasireotide in clinical practice had a mild to moderate hypercortisolism and a median shorter duration of pasireotide treatment compared to patients enrolled in randomized trials ( 7 vs. 18 months; $\mathrm{p}=0.04$ ). Baseline and follow-up features of the study population according to treatment setting are reported in Table S1. UFC data during pasireotide treatment for each patient are detailed in $\odot$ Table 2.

A positive correlation was found between UFC percentage change at month 3 and UFC percentage change at last follow-up $(\mathrm{r}=0.52 ; \mathrm{p}=0.02)$. No significant correlation was found between UFC percentage change at both time-points and baseline UFC values.

\section{Plasma ACTH, morning serum cortisol and LNSC}

Mean plasma ACTH and morning serum cortisol decreased from baseline to last follow-up evaluation. The mean percentage change $( \pm$ SD) from baseline values in plasma ACTH levels was $-20.9 \%$ $( \pm 40.7 \%)$ at month 3 and $-35.7 \%( \pm 38.7 \%)$ at last follow-up. Compared to baseline values, the ACTH reduction was significant at both time-points $(65.5 \pm 23.3 \mathrm{pg} / \mathrm{ml}$ vs. $46.8 \pm 16.9 \mathrm{pg} / \mathrm{ml}$, $\mathrm{p}=0.007$, at month $3 ; 65.5 \pm 23.3 \mathrm{pg} / \mathrm{ml}$ vs. $42 \pm 23.4 \mathrm{pg} / \mathrm{ml}$, $\mathrm{p}=0.001$, at last follow-up).

Mean serum morning cortisol levels were almost unchanged from baseline levels to month $3(23.3 \pm 6.3 \mu \mathrm{g} / \mathrm{dl}$ vs. $22.6 \pm 8.03 \mu \mathrm{g} /$ $\mathrm{dl} ; \mathrm{p}=0.7$ ), while significantly reduced when baseline values were compared to serum cortisol levels at last follow-up evaluation $(23.3 \pm 6.3 \mu \mathrm{g} / \mathrm{dl}$ vs. $19.2 \pm 6.7 \mu \mathrm{g} / \mathrm{dl} ; \mathrm{p}=0.01$; mean percentage change from baseline to last follow-up $-17.5 \pm 30.4 \%$ ).

A positive correlation was found between plasma ACTH percentage change at month 3 and plasma ACTH percentage change at last follow-up $(r=0.79 ; \mathrm{p}<0.01)$ as well as plasma ACTH percentage change and serum morning cortisol percentage change at last follow-up $(r=0.47 ; p=0.04)$. A negative correlation was found between plasma ACTH percentage change at month 3 and baseline plasma ACTH values $(r=-0.56 ; p=0.02)$.

Long-term data on LNSC levels during pasireotide treatment were available only for $14 / 20$ patients. The mean percentage change $( \pm S D)$ from baseline values in LNSC levels was $-22.5 \%$ $( \pm 55 \%)$ at month 3 and $-28.3 \%( \pm 58.3 \%)$ at last follow-up with a normalization rate of about $71 \%(10 / 14)$ at last follow-up. The 10 patients who normalized LNSC levels at month 3, showed sustained normalized LNSC levels at last follow-up. Normalization of LNSC was associated with normalized UFC levels in 7/10 patients. A positive correlation was found between LNSC percentage change and UFC percentage change at last follow-up $(\mathrm{r}=0.67 ; \mathrm{p}=0.009)$. Compared to baseline values the reduction in LNSC levels was significant at both time-points $(\mathrm{p}<0.05)$.

\section{Clinical and biochemical parameters}

Treatment with pasireotide was associated with significant clinical improvement. Body weight improved in about $70 \%$ of patients $(14 / 20)$. The mean changes $( \pm$ SD) in body weight were $-6.9 \mathrm{~kg}( \pm 9.8 \mathrm{~kg})$ from baseline to month $3(84.8 \pm 18.5 \mathrm{~kg}$ vs. $77.8 \pm 20.2 \mathrm{~kg} ; \mathrm{p}=0.006)$ and $-9.9 \mathrm{~kg}( \pm 11.7 \mathrm{~kg})$ from baseline to last follow-up ( $84.8 \pm 18.5 \mathrm{~kg}$ vs. $73.5 \pm 21 \mathrm{~kg} ; \mathrm{p}=0.001)$. Waist circumference values significantly decreased from baseline to last follow-up ( $100.3 \pm 14.3 \mathrm{~cm}$ vs. $87 \pm 13.5 \mathrm{~cm}$; $\mathrm{p}=0.003)$.

Blood pressure improved in about $70 \%$ of patients $(14 / 20)$. The prevalence of hypertension significantly reduced from baseline to last follow-up ( 85 vs. $65 \%$; $=0.031$ ). The mean changes $( \pm S D$ ) in arterial blood pressure from baseline to last follow-up were $-10.2 \mathrm{mmHg}( \pm 17.3 \mathrm{mmHg})$ for SBP $(133.7 \pm 13.9 \mathrm{mmHg}$ vs.
$123.5 \pm 10.9 \mathrm{mmHg} ; \mathrm{p}=0.016)$ and $-5.2 \mathrm{mmHg}( \pm 8.2 \mathrm{mmHg})$ for DBP $(89 \pm 10 \mathrm{mmHg}$ vs. $83.8 \pm 6.1 \mathrm{mmHg} ; \mathrm{p}=0.011)$. Among the $14 \mathrm{CD}$ patients with blood pressure improvement during pasireotide treatment, improvement was more frequent in patients with concomitant body weight decrease (85.7 vs. $33.3 \%$; $\mathrm{p}=0.037)$.

When patients were divided according to UFC response at last follow-up (controlled, partially controlled and uncontrolled), no significant differences were found in the percentage of patients achieving improved body weight and/or blood pressure ( $\bullet$ Fig. 2). Data about BMI and blood pressure during pasireotide treatment for each patient are detailed in 0 Table 2 .

Regarding lipid profile, changes in total cholesterol, LDL, HDL, and serum triglycerides levels during pasireotide treatment were not statistically significant. It should be noted, however, that serum triglycerides showed a trend toward increased levels at month $3(129 \pm 54 \mathrm{mg} / \mathrm{dl} \mathrm{vs} .151 \pm 88 \mathrm{mg} / \mathrm{dl} ; \mathrm{p}=0.08)$ followed by a subsequent decrease reaching mean values of $134 \pm 68 \mathrm{mg} /$ dl at last follow-up.

\section{Glucose profile}

As expected, glucose and HbA1c levels increased soon after pasireotide initiation but stabilized after initiation of glucose lowering interventions ( $\odot$ Table 3 ). At baseline $40 \%$ of patients $(8 / 20)$ were diabetics but only 2 of them were treated with pharmacological approaches (basal-bolus insulin in one case and basal insulin plus metformin in the second case). The others managed with diet and lifestyle interventions. A prediabetic state was detected in $25 \%$ of patients (5/20) while $35 \%(7 / 20)$ had a normal glucose tolerance (NGT) state. At month $3,70 \%$ of patients $(14 / 20)$ were diabetics, $25 \%(5 / 20)$ had a prediabetic state, and one patient maintained a NGT state.

At last follow-up $85 \%$ of patients (17/20) were diabetics, $10 \%$ (2/20) had a prediabetic state, and one patient maintained a NGT state. All the 5 patients with a prediabetic state at baseline progressed to a diabetic state at last follow-up. Treatment with pasireotide induced a NODAP in $28 \%$ of patients $(2 / 7)$ at month 3 ; this rate increased to $57 \%(4 / 7)$ at last follow-up.

FPG levels increased after initiation of pasireotide treatment with a mean $( \pm \mathrm{SD})$ change from baseline of $62 \mathrm{mg} / \mathrm{dl}( \pm 67 \mathrm{mg} / \mathrm{dl})$ at month $3(85.5 \pm 10.5 \mathrm{mg} / \mathrm{dl}$ vs. $148.2 \pm 73.4 \mathrm{mg} / \mathrm{dl} ; \mathrm{p}=0.003)$ and $46 \mathrm{mg} / \mathrm{dl}( \pm 55 \mathrm{mg} / \mathrm{dl})$ at last follow-up $(85.5 \pm 10.5 \mathrm{mg} / \mathrm{dl} \mathrm{vs}$. $139.8 \pm 47.0 \mathrm{mg} / \mathrm{dl} ; \mathrm{p}=0.005)$.

Consistent with increases in FPG, the mean changes $( \pm S D)$ in HbA1c levels were $17 \mathrm{mmol} / \mathrm{mol}( \pm 14 \mathrm{mmol} / \mathrm{mol})$ from baseline to month $3(37 \pm 4.7 \mathrm{mmol} / \mathrm{mol}$ vs. $54 \pm 15.2 \mathrm{mmol} / \mathrm{mol} ; \mathrm{p}=0.001)$ and $14 \mathrm{mmol} / \mathrm{mol}( \pm 8.6 \mathrm{mmol} / \mathrm{mol})$ from baseline to last followup $(37 \pm 4.7 \mathrm{mmol} / \mathrm{mol}$ vs. $53 \pm 8.5 \mathrm{mmol} / \mathrm{mol} ; \mathrm{p}=0.001)$.

The greatest increase in HbA1c levels occurred during the first 3 months of pasireotide treatment to stabilize thereafter. The trend of HbA1c levels during the first 3 months of treatment was similar to that observed for serum triglycerides. A significant positive correlation was found between HbA1c levels and serum triglycerides both at month $3(\mathrm{r}=0.59 ; \mathrm{p}=0.02)$ and at last follow-up $(\mathrm{r}=0.55 ; \mathrm{p}=0.01)$.

In patients not receiving glucose-lowering medications at baseline, at least one medication was started during pasireotide treatment in 8 out of 18 patients (44\%). All these patients except 2 achieved a satisfactory glucose control ( $\bullet$ Table 3 ). We did not find any association between UFC response and glycemic control during pasireotide treatment. Data about glucose profile and 


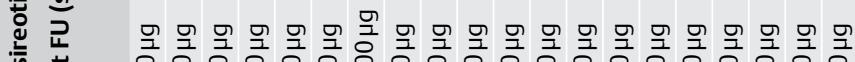

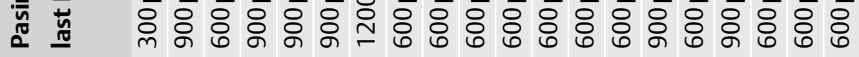

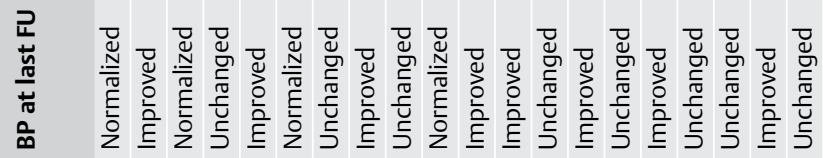

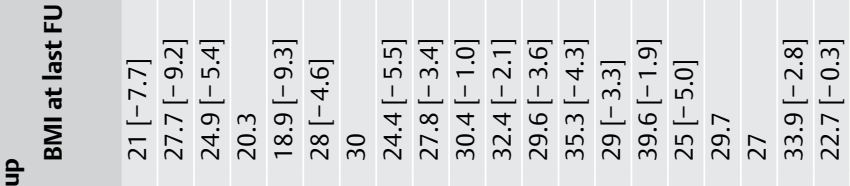

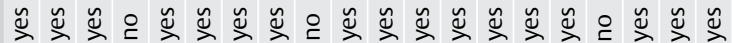
穴

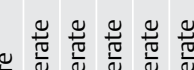

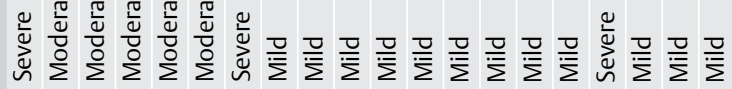

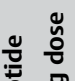

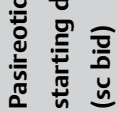

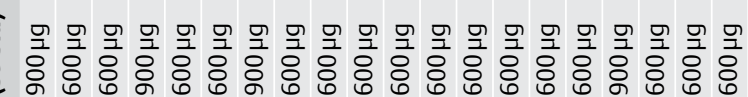

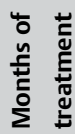

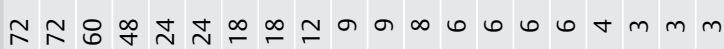

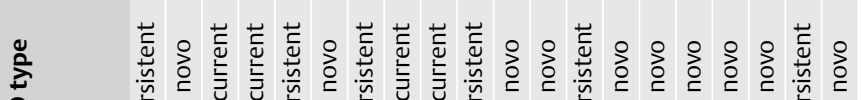

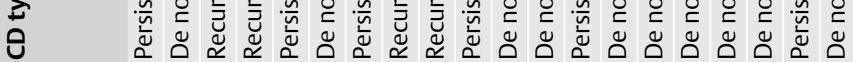

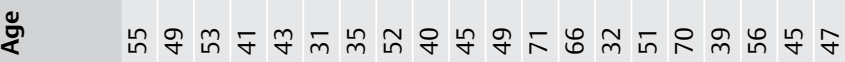

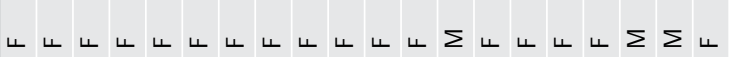

号

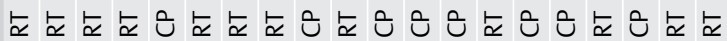

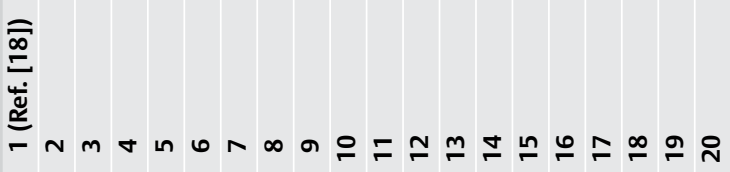


UFC response to treatment for each patient are reported in $\odot$ Table 3.

Patients who developed a NODAP or experienced a worsening of pre-existing diabetes or prediabetes during pasireotide treatment (17/20) compared to the 3 patients with NGT or a prediabetic state at last visit showed, at baseline, a significantly higher body weight $(86.9 \pm 17.7$ vs. $64.2 \pm 14.8 \mathrm{~kg})$, BMI $(32.4 \pm 4.2$ vs. $\left.24.1 \pm 5.0 \mathrm{~kg} / \mathrm{m}^{2}\right)$ and waist circumference $(103.6 \pm 11.2$ vs. $85.6 \pm 15.9 \mathrm{~cm})$. Conversely there were no significant differences in gender, age, mean daily pasireotide dose, FPG, HbA1c, insulin fasting level, and HOMA-IR at baseline. A positive family history for diabetes was reported by $60 \%$ of diabetic patients.

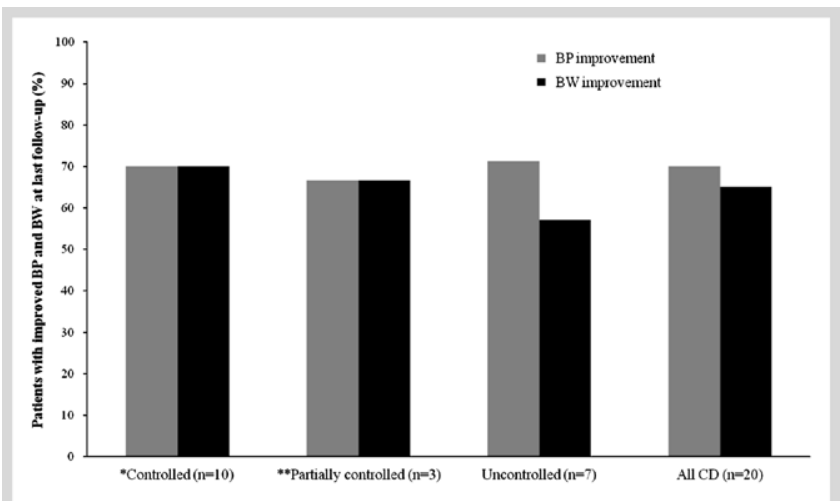

Fig. 2 Percentage of patients with improved blood pressure (BP) and body weight (BW) according to UFC response at last follow-up. $\left({ }^{*}\right.$ Controlled = patients with normalized UFC levels at last follow-up; * * Partially controlled = patients with $\geq 40 \%$ UFC reduction from baseline values without normalization).

\section{Tumor volume}

Fourteen patients (70\%) had a measurable pituitary tumor on MRI at initial diagnosis ( $\odot$ Table 1). However, only 10 patients (50\%) had a measurable pituitary tumor on MRI at baseline and no significant changes occurred during pasireotide treatment.

\section{Predictive factors of response to pasireotide treatment} In the overall population, the response rate to pasireotide treatment was $12 / 20$ (60\%). Two patients reduced UFC levels without normalization but were considered responsive to treatment for the significant clinical improvement achieved. The majority of responder patients (9/12) showed normalized UFC levels at month 3 ( 75 vs. $12.5 \%$ in the nonresponder group; $p=0.01$ ).

No significant differences were found between responders and nonresponders to pasireotide treatment in baseline features such as age, sex, disease severity, disease type, plasma ACTH, morning serum cortisol, LNSC, and UFC levels as well as response to dynamic test (CRH and DDAVP stimulation test; $1 \mathrm{mg}$ DST).

Logistic regression analysis showed that response to treatment was independent from baseline features (age, sex, disease severity, disease type, plasma ACTH, morning serum cortisol, LNSC, and UFC levels) as well as duration of pasireotide treatment and hormonal response at month 3.

The prognostic profiles of the UFC and LNSC percentage change from baseline to month 3 in predicting response to treatment with pasireotide was evaluated using ROC curve analysis.

A reduction $\geq 43 \%$ in UFC levels at month 3 was able to predict response to treatment with $63 \%$ sensitivity (SE) and $62 \%$ specificity (SP) while a reduction $\geq 43 \%$ in LNSC values at month 3 was associated with a $62.2 \% \mathrm{SE}$ and $75 \% \mathrm{SP}$ in predicting response to treatment. All the other cutoff points were associated with a worse prognostic profile.

Table 3 Glucose profile changes during pasireotide treatment for each patient.

\begin{tabular}{|c|c|c|c|c|c|c|c|c|}
\hline \multirow[t]{2}{*}{ Patient } & \multicolumn{3}{|c|}{ Glycemic status } & \multirow{2}{*}{$\begin{array}{l}\text { Months of } \\
\text { treatment }\end{array}$} & \multirow{2}{*}{$\begin{array}{l}\Delta \mathrm{HbA} 1 \mathrm{c} \\
(\mathrm{mmol} / \mathrm{mol})\end{array}$} & \multirow[t]{2}{*}{ Glucose lowering interventions } & \multirow{2}{*}{$\begin{array}{l}\text { Glycemic } \\
\text { control }\end{array}$} & \multirow{2}{*}{$\begin{array}{l}\text { UFC at last } \\
\text { FU }\end{array}$} \\
\hline & Baseline & Month 3 & Last FU & & & & & \\
\hline 1 (Ref. [18]) & $\mathrm{DM}^{*}$ & DM & DM & 72 & 0 & basal-bolus insulin $\rightarrow$ metformin + DPP-4 inhibitor & PC & Normalized \\
\hline 2 & $\mathrm{DM}$ & DM & DM & 72 & +24 & metformin + glimepiride $\rightarrow$ glimepiride & PC & Reduced \\
\hline 3 & NGT & NGT & $\mathrm{DM}$ & 60 & +13 & diet and lifestyle & $\mathrm{T}$ & Normalized \\
\hline 4 & DM & Pre-DM & Pre-DM & 48 & +14 & diet and lifestyle & $\mathrm{T}$ & Reduced \\
\hline 5 & DM & DM & $\mathrm{DM}$ & 24 & +28 & $\begin{array}{l}\text { metformin } \rightarrow \text { DPP- } 4 \text { inhibitor } \rightarrow \text { GLP- } 1 \text { analogue } \\
\rightarrow \text { GLP-1 analogue }+ \text { detemir } \rightarrow \text { basal-bolus insulin }\end{array}$ & PC & Reduced \\
\hline 6 & Pre-DM & NGT & DM & 24 & +17 & diet and lifestyle & $\mathrm{T}$ & Reduced \\
\hline 7 & NGT & NGT & DM & 18 & +17 & diet and lifestyle & $\mathrm{T}$ & Reduced \\
\hline 8 & NGT & DM & DM & 18 & +19 & metformin & PC & Reduced \\
\hline 9 & Pre-DM & DM & DM & 12 & +7 & diet and lifestyle & $\mathrm{T}$ & Normalized \\
\hline 10 & NGT & DM & DM & 9 & +10 & diet and lifestyle & $\mathrm{T}$ & Normalized \\
\hline 11 & Pre-DM & $\mathrm{DM}$ & $\mathrm{DM}$ & 9 & +24 & glimepiride & UC & Normalized \\
\hline 12 & DM & DM & DM & 8 & +3 & metformin & $\mathrm{T}$ & Normalized \\
\hline 13 & $\mathrm{DM}$ & DM & DM & 6 & +14 & $\begin{array}{l}\text { metformin + DPP- } 4 \text { inhibi- } \\
\text { tor + glargine } \rightarrow \text { metformin + DPP- } 4 \text { inhibitor }\end{array}$ & PC & Normalized \\
\hline 14 & NGT & DM & DM & 6 & +8 & metformin + glimepiride & $\mathrm{T}$ & Reduced \\
\hline 15 & DM & DM & DM & 6 & +10 & diet and lifestyle & PC & Normalized \\
\hline 16 & Pre-DM & DM & DM & 6 & +22 & diet and lifestyle & PC & Normalized \\
\hline 17 & NGT & NGT & NGT & 4 & 0 & diet and lifestyle & $\mathrm{T}$ & Normalized \\
\hline 18 & $\mathrm{DM}^{*}$ & DM & DM & 3 & +16 & metformin + glargine $\rightarrow$ metformin + glargine & $\mathrm{T}$ & Unchanged \\
\hline 19 & Pre-DM & DM & DM & 3 & +26 & diet and lifestyle & UC & Unchanged \\
\hline 20 & NGT & Pre-DM & Pre-DM & 3 & +7 & diet and lifestyle & $\mathrm{T}$ & Reduced \\
\hline
\end{tabular}

FU: Follow-up; UFC: Urinary free cortisol; DM: Diabetes mellitus; Pre-DM: Prediabetes; NGT: Normal glucose tolerance; T: Target (HbA1c <53 mmol/mol); PC: Poor control (HbA1c $53-64 \mathrm{mmol} / \mathrm{mol}$ ); UC: Uncontrolled (HbA1c>64 mmol/mol)

* Diabetic patients treated with pharmacological approach at baseline 


\section{Adverse events}

The safety profile of pasireotide in our experience was similar to the safety profile of other somatostatin analogues with respect to adverse events such as gastrointestinal symptoms and gallstones, except for the higher frequency of hyperglycemia with pasireotide.

Glucose changes during pasireotide treatment in our patients have been previously detailed. It should be noted however that no patient discontinued treatment for hyperglycemia-related AEs. The most frequently reported AEs were grade 1 or 2 gastrointestinal disorders (diarrhoea, abdominal pain and decreased appetite) that in the majority of patients occurred in the first month of treatment and spontaneously resolved without intervention.

One patient discontinued treatment for persistent diarrhoea, which occurred at month 18 and in one patient gastrointestinal symptoms required pasireotide dose reduction. Of the 18 patients with normal gallbladder on ultrasonographic examination at baseline, $6(33 \%)$ who developed gallstones at month 6 or 9 were treated with ursodesoxycholic acid. A mild and transient elevation in liver enzyme levels occurred in 2 patients (10\%), normalized with continued pasireotide treatment.

Hypocortisolism-related adverse events were reported in 2 patients $(10 \%)$. This condition resolved with a reduction in the pasireotide dose or temporary interruption of treatment. No patients had QT interval alterations or significant electrocardiographic changes.

\section{Discussion}

$\nabla$

The results of our study confirm the efficacy and safety of pasireotide even in the long-term in a considerable percentage of $C D$ patients. The median duration of pasireotide treatment is 9 months (range 3-72 months) with 3 patients treated for more than 4 years without loss of efficacy. UFC normalization occurred in $50 \%$ of patients and biochemical as well as clinical response to treatment was observed in about $60 \%$ of patients. In 2 patients, UFC normalization was achieved by increasing pasireotide dosage. Compared to results of both the Phase III study and the Phase II extension study $[8,10,11]$ a greater percentage of our patients achieved normalized UFC levels during medium/longterm treatment with pasireotide. However, when our patients were evaluated according to treatment setting (clinical practice vs. randomized trials), patients treated with pasireotide in dayto-day clinical practice showed a trend towards a higher rate of normalized UFC levels compared to those enrolled in randomized trials ( 75 vs. $33 \%$ ). It should be noted that the majority of patients treated with pasireotide in clinical practice had mild hypercortisolism. Thus, it is reasonable to assume that the discrepancies observed in the percentage of $\mathrm{CD}$ patients responsive to treatment are probably related to the higher prevalence of mild hypercortisolism in our cohort of patients than that reported in clinical trials. Normalization of UFC levels during follow-up seems more likely to be achieved in patients with lower baseline levels than in patients with higher baseline levels suggesting a greater effectiveness of pasireotide in mild hypercortisolism. However, when our patients were evaluated according to disease severity the prevalence of UFC normalization was similar in patients with mild, moderate or severe hypercortisolism. In addition, while UFC response (normalization or reduction) to pasireotide in the first months of treatment seems to be predictive of long-term response in patients with mild and moderate hypercortisolism, in our experience patients with severe hypercortisolism seem to achieve additional UFC reduction during continuative treatment with pasireotide leading to a delayed UFC normalization [18]. In line with this consideration, CD patients treated with pasireotide have to be evaluated in the first months of treatment not only for biochemical efficacy but also for clinical benefit taking into account that the improvement in UFC levels during pasireotide treatment may require several months and that blood pressure and/or body weight may improve regardless of UFC response. As expected CD patients treated with pasireotide in clinical practice had a median shorter duration of treatment than patients enrolled in clinical trials (7 vs. 18 months). This difference should not be considered as a bias for the increased prevalence of normalized UFC levels observed in clinical practice. In our extensive experience, the benefit achieved during pasireotide treatment is sustained over time without escape phenomenon in the long-term. Pasireotide seems to be useful also as short-term pre-surgical treatment in critically ill CD patients [19]. In our population, 2 patients with de novo $C D$ were treated with pasireotide for 6 months in clinical practice in order to improve clinical and biochemical parameters before pituitary surgery. In both cases, a normalized UFC was achieved as well as a significant clinical improvement followed by an effective surgical treatment without complications during surgery or in the post-surgical period.

Looking for possible predictive factors of long-term response to pasireotide, we evaluated the UFC percentage change in the first months of treatment using a ROC curve analysis. Unfortunately no cutoff values achieved a satisfactory prognostic profile.

It should be remembered that UFC assessment has several limitations mainly related to analytic issues and the high withinsubject variability observed in patients with endogenous hypercortisolism [20,21]. For these reasons it is advisable that biochemical response to pasireotide be defined not only on the basis of UFC levels but also using further biochemical markers, such as LNSC. The combined evaluation of UFC and LNSC seems to provide additional information on the achievement of adequate disease control during medical treatment [22-25]. In our experience, there is a strong relationship between UFC and LNSC levels. In particular, the majority of patients (7/10) with normalized UFC during pasireotide treatment achieved normalized LNSC even in the long-term.

To identify early $C D$ patients responsive to treatment with pasireotide, we also analyzed baseline features of our patients. Unfortunately no significant baseline predictive factors were found. However, our previous data suggest the usefulness of an acute pasireotide suppression test (PST) in predicting long-term response to pasireotide in patients with $\mathrm{CD}$ [26]. In particular, we found that an LNSC percentage fall $>27 \%$ as well as a normalization of this parameter during PST is associated with a probability of $100 \%$ of achieving a favorable response to pasireotide treatment in the medium/long term [26].

About the effect of pasireotide on tumor mass, a recent publication [27] focusing on this topic demonstrated the marked reduction in tumor size in a small cohort of $C D$ patients after 6-12 months of pasireotide treatment until the complete disappearance of pituitary tumor in one case.

Conversely, no significant changes in tumor volume occurred during pasireotide treatment in our patients. It should be specified, however, that all patients except one with a measurable pituitary lesion at baseline had a microadenoma or a minimal 
post-surgical residual tumor. Therefore, the apparent lack of reduction in pituitary tumor size observed in our patients seems to be more probably related to the difficulty in appreciating significant changes in patients with very minimal pituitary lesions, despite the neuro-radiologist experience. One patient had a pituitary macroadenoma but he was treated with pasireotide only for 6 months and in this period no significant changes were found.

Our extensive experience with pasireotide in CD also supports its long-term safety. Pasireotide had a safety profile similar to that of first-generation somatostatin analogues, except for the increased frequency of hyperglycemia. Hyperglycemia is a wellcharacterized effect of pasireotide treatment [28], however, in our experience it was more easily managed than expected with no patients discontinuing treatment for this AE. Glucose metabolism impairment is a common complication of endogenous hypercortisolism. Epidemiological data report a prevalence of overt diabetes mellitus in patients with Cushing's syndrome (CS) ranging from 20 to $50 \%[5,29]$. However, as these frequencies are mainly based on measurement of fasting blood glucose, the real impact of hypercortisolism on glucose profile is not completely known and probably greatly underestimated [5]. Fasting blood glucose is often normal in endogenous hypercortisolism and glucose metabolism impairment is more frequent in the postprandial period and rarely investigated [5]. All patients with CS should be investigated for glucose profile alterations with OGTT and HbA1c measurement. In our cohort of patients the prevalence of diabetes mellitus at baseline was carefully evaluated resulting in about $40 \%$. This prevalence increased to $85 \%$ during pasireotide treatment.

The impact of pasireotide on glucose metabolism in CD is complex and this drug may worsen a pre-existing prediabetes/diabetes as well as induce a NODAP [30,31]. At baseline overt diabetes mellitus was detected in $40 \%$ of our CD patients while $25 \%$ of them showed a prediabetic state. Therefore a glucose profile impairment was present at baseline in $65 \%$ of patients. Conversely only 7 patients had an NGT state at baseline and 4 of them (57\%) developed overt diabetes mellitus during pasireotide treatment. Therefore, only in these patients the definition of NODAP may be strictly applied. These data confirm the significant impact of pasireotide on glucose metabolism in CD but at the same time highlight the need for a careful evaluation of the glucose profile before starting pasireotide administration to identify patients at greatest risk of developing hyperglycemiarelated AEs during treatment. In our experience all patients with a prediabetic state at baseline become diabetic during pasireotide treatment. Our results suggest also that risk factors for diabetes mellitus during pasireotide treatment seem to include a positive family history such as obesity and increased waist circumference.

Our data confirm that glucose impairment occurred soon after pasireotide initiation (first 1-3 months) and stabilized after glucose lowering interventions. In particular, in our experience, hyperglycemia was easily managed with only diet and lifestyle intervention in about half of patients. In patients not receiving glucose-lowering medications at baseline, at least one medication was started during pasireotide treatment only in $44 \%$ of patients with a satisfactory glucose control in the majority of them. Therefore, the clinical impact of this AE appears lower than expected.
Studies in healthy volunteers showed that hyperglycemia associated with pasireotide treatment results from a decrease in incretin and insulin secretion, with no change in insulin sensitivity [28]. Based on these data, recent expert reports recommend the preferential use of GLP-1 based-medications for the management of hyperglycemia during pasireotide in $\mathrm{CD}[30,31]$.

These recommendations were applied in our patients only in recent years while metformin, if not contraindicated and if tolerated, was our preferred initial pharmacological agent with quite a good response. The important role of metformin in patients with $C D$ is supported by the beneficial effect on insulin resistance (a typical feature of patients with $C D$ ) and by the additional inhibitory effect on visceral adipose tissue accumulation mediated by the adenosine monophosphate-activated protein kinase (AMPK) [32].

It should be noted, however, that no interventional studies have been performed in patients with $\mathrm{CD}$ to investigate the physiopathology of pasireotide induced hyperglycemia and it is possible that mechanisms are different from that reported in healthy subjects. Further investigations in this topic are needed.

In line with previous data [9], even in our patients glucose control during pasireotide treatment was independent from UFC response. It remains unclear why UFC normalization was not associated with diabetes mellitus improvement although single case reports suggest the possible recuperation of an NGT state [25] as well as the significant improvement of pre-existing diabetes mellitus after continued use of pasireotide and control of underlying hypercortisolism $[18,33]$.

Given the high risk of progression of prediabetes to diabetes, we suggest to consider glucose-lowering interventions (lifestyle changes and/or metformin) before pasireotide initiation in patients with a prediabetic state. Pre-existing diabetes mellitus is not a contraindication to pasireotide treatment and control of $\mathrm{CD}$ may outweigh any negative effects of the drug on glucose metabolism [18,33].

As for the first-generation somatostatin analogues gastrointestinal disturbances, even generally transient and of mild-to-moderate degree, represent the most frequent $\mathrm{AE}$ during pasireotide treatment. A relatively high percentage of our patients (33\%) developed gallstones after 6-9 months of pasireotide treatment. Considering this data a close and careful monitoring of gallbladder ultrasound is recommended.

In conclusion, although apparently in a limited number of cases, our experience supports the extended treatment with pasireotide in CD in clinical practice. Pasireotide treatment is associated with sustained biochemical and clinical benefits in about $60 \%$ of $\mathrm{CD}$ patients. Glucose profile alterations are a frequent complication of pasireotide treatment; however this AE seems to be easily managed with diet and lifestyle intervention in almost half of the patients.

\section{Acknowledgements}

$\nabla$

The Authors would like to thank Prof. G. Angeletti, University of Perugia, for her contribution.

\section{Conflict of Interest \\ $\nabla$}

The authors declare no conflict of interest. 


\section{References}

1 Lacroix A, Feelders RA, Stratakis CA, Nieman LK. Cushing's syndrome. Lancet 2015; 386: 913-927

2 Juszczak A, Ertorer ME, Grossman A. The therapy of Cushing's disease in adults and children: an update. Horm Metab Res 2013; 45: 109-117

3 Biller BM, Grossman AB, Stewart PM, Melmed S, Bertagna X, Bertherat J, Buchfelder M, Colao A, Hermus AR, Hofland LJ, Klibanski A, Lacroix A, Lindsay JR, Newell-Price J, Nieman LK, Petersenn S, Sonino N, Stalla GK, Swearingen B, Vance ML, Wass JA, Boscaro M. Treatment of adrenocorticotropin-dependent Cushing's syndrome: a consensus statement. J Clin Endocrinol Metab 2008; 93: 2454-2462

4 Nieman LK, Biller BM, Findling JW, Murad MH, Newell-Price J, Savage MO, Tabarin A. Treatment of Cushing's Syndrome: An Endocrine Society Clinical Practice Guideline. J Clin Endocrinol Metab 2015; 100 : 2807-2831

5 Arnaldi G, Mancini T, Tirabassi G, Trementino L, Boscaro M. Advances in the epidemiology, pathogenesis, and management of Cushing's syndrome complications. J Endocrinol Invest 2012; 35: 434-448

6 Clayton RN, Raskauskiene D, Reulen RC, Jones PW. Mortality and morbidity in Cushing's disease over 50 years in Stoke-on-Trent, UK: audit and meta-analysis of literature. J Clin Endocrinol Metab 2011; 96: 632-642

7 Graversen D, Vestergaard P, Stochholm K, Gravholt CH, Jørgensen JO. Mortality in Cushing's syndrome: a systematic review and metaanalysis. Eur J Intern Med 2012; 23: 278-282

8 Colao A, Petersenn S, Newell-Price J, Findling JW, Gu F, Maldonado M, Schoenherr U, Mills D, Salgado LR, Biller BM, Pasireotide B2305 Study Group. A 12-month phase 3 study of pasireotide in Cushing's disease. N Engl J Med 2012; 366: 914-924

9 Pivonello R, Petersenn S, Newell-Price J, Findling JW, Gu F, Maldonado M, Trovato A, Hughes G, Salgado LR, Lacroix A, Schopohl J, Biller BM, Pasireotide B2305 Study Group. Pasireotide treatment significantly improves clinical signs and symptoms in patients with Cushing's disease: results from a Phase III study. Clin Endocrinol (Oxf) 2014; 81: 408-417

10 Boscaro M, Bertherat J, Findling J, Fleseriu M, Atkinson AB, Petersenn S, Schopohl J, Snyder P, Hughes G, Trovato A, Hu K, Maldonado M, Biller BM. Extended treatment of Cushing's disease with pasireotide: results from a 2-year, Phase II study. Pituitary 2014; 17: 320-326

11 Schopohl J, Gu F, Rubens R, Van Gaal L, Bertherat J, Ligueros-Saylan M, Trovato A, Hughes G, Salgado LR, Boscaro M, Pivonello R. Pasireotide can induce sustained decreases in urinary cortisol and provide clinical benefit in patients with Cushing's disease: results from an openended, open-label extension trial. Pituitary 2015; 18: 604-612

12 Arnaldi G, Angeli A, Atkinson AB, Bertagna X, Cavagnini F, Chrousos GP, Fava GA, Findling JW, Gaillard RC, Grossman AB, Kola B, Lacroix A, Mancini T, Mantero F, Newell-Price J, Nieman LK, Sonino N, Vance ML, Giustina A, Boscaro M. Diagnosis and complications of Cushing's syndrome: a consensus statement. J Clin Endocrinol Metab 2003; 88: 5593-5602

13 Nieman LK, Biller BM, Findling JW, Newell-Price J, Savage MO, Stewart PM, Montori VM. The diagnosis of Cushing's syndrome: an Endocrine Society Clinical Practice Guideline. J Clin Endocrinol Metab 2008; 93: $152-640$

14 Boscaro M, Ludlam WH, Atkinson B, Glusman JE, Petersenn S, Reincke M, Snyder P, Tabarin A, Biller BM, Findling J, Melmed S, Darby $\mathrm{CH}, \mathrm{Hu} K$, Wang Y, Freda PU, Grossman AB, Frohman LA, Bertherat J. Treatment of pituitary-dependent Cushing's disease with the multireceptor ligand somatostatin analog pasireotide (SOM230): a multicenter, phase II trial. J Clin Endocrinol Metab 2009; 94: 115-122

15 Perk J, De Backer G, Gohlke H, Graham I, Reiner Z, Verschuren WM, Albus C, Benlian P, Boysen G, Cifkova R, Deaton C, Ebrahim S, Fisher M, Germano G, Hobbs R, Hoes A, Karadeniz S, Mezzani A, Prescott E, Ryden L, Scherer M, Syvänne M, Scholte Op Reimer WJ, Vrints C, Wood D, Zamorano JL, Zannad F, Fifth Joint Task Force of the European Society of Cardiology and Other Societies on Cardiovascular Disease Prevention in Clinical Practice; European Association for Cardiovascular Prevention and Rehabilitation. European Guidelines on cardiovascular disease prevention in clinical practice (version 2012): The Fifth Joint Task Force of the European Society of Cardiology and Other Societies on Cardiovascular Disease Prevention in Clinical Practice (constituted by representatives of nine societies and by invited experts). Atherosclerosis 2012; 223: 1-68

16 American Diabetes Association. Standards of medical care in diabetes-2014. Diabetes Care 2014; 37 (Suppl 1): S14-S80
17 Matthews DR, Hosker JP, Rudenski AS, Naylor BA, Treacher DF, Turner RC. Homeostasis model assessment: insulin resistance and beta-cell function from fasting plasma glucose and insulin concentrations in man. Diabetologia 1985; 28: 412-419

18 Trementino L, Cardinaletti M, Concettoni C, Marcelli G, Boscaro M, Arnaldi G. Up-to 5-year efficacy of pasireotide in a patient with Cushing's disease and pre-existing diabetes: literature review and clinical practice considerations. Pituitary 2015; 18: 359-365

19 Cannavo S, Messina E, Albani A, Ferrau F, Barresi V, Priola S, Esposito F, Angileri F. Clinical management of critically ill patients with Cushing's disease due to ACTH-secreting pituitary macroadenomas: effectiveness of presurgical treatment with pasireotide. Endocrine $2015 \mathrm{Apr}$ 16 [Epub ahead of print]

20 Raff H, Auchus RJ, Findling JW, Nieman LK. Urine free cortisol in the diagnosis of Cushing's syndrome: is it worth doing and, if so, how? J Clin Endocrinol Metab 2015; 100: 395-397

21 Petersenn S, Newell-Price J, Findling JW, Gu F, Maldonado M, Sen K, Salgado LR, Colao A, Biller BM, Pasireotide B2305 Study Group. High variability in baseline urinary free cortisol values in patients with Cushing's disease. Clin Endocrinol (Oxf) 2014; 80: 261-269

22 Trementino L, Cardinaletti M, Concettoni C, Marcelli G, Polenta B, Spinello M, Boscaro M, Arnaldi G. Salivary cortisol is a useful tool to assess the early response to pasireotide in patients with Cushing's disease. Pituitary 2015; 18: 60-67

23 van der Pas R, de Bruin C, Pereira AM, Romijn JA, Netea-Maier RT, Hermus AR, Zelissen PM, de Jong FH, van der Lely AJ, de Herder WW, Webb $S M$, Lamberts SW, Hofland LJ, Feelders RA. Cortisol diurnal rhythm and quality of life after successful medical treatment of Cushing's disease. Pituitary 2013; 16: 536-544

24 Barbot M, Albiger N, Ceccato F, Zilio M, Frigo AC, Denaro L, Mantero F, Scaroni $C$. Combination therapy for Cushing's disease: effectiveness of two schedules of treatment. Should we start with cabergoline or ketoconazole? Pituitary 2014; 17: 109-117

25 MacKenzie Feder J, Bourdeau I, Vallette S, Beauregard H, Ste-Marie LG, Lacroix A. Pasireotide monotherapy in Cushing's disease: a singlecentre experience with 5-year extension of phase III Trial. Pituitary 2014; 17: 519-529

26 Trementino L, Zilio M, Marcelli G, Michetti G, Barbot M, Ceccato F, Boscaro M, Scaroni C, Arnaldi G. The role of an acute pasireotide suppression test in predicting response to treatment in patients with Cushing's disease: findings from a pilot study. Endocrine 2015; 50: 154-161

27 Simeoli C, Auriemma RS, Tortora F, De Leo M, Iacuaniello D, Cozzolino A, De Martino MC, Pivonello C, Mainolfi CG, Rossi R, Cirillo S, Colao A, Pivonello $R$. The treatment with pasireotide in Cushing's disease: effects of long-term treatment on tumor mass in the experience of a single center. Endocrine 2015; 50: 725-740

28 Henry RR, Ciaraldi TP, Armstrong D, Burke P, Ligueros-Saylan $M$, Mudaliar S. Hyperglycemia associated with pasireotide: results from a mechanistic study in healthy volunteers. J Clin Endocrinol Metab 2013; 98: 3446-3453

29 Valassi E, Santos A, Yaneva M, Tóth M, Strasburger CJ, Chanson P, Wass $J A$, Chabre O, Pfeifer M, Feelders RA, Tsagarakis S, Trainer PJ, Franz $H$, Zopf K, Zacharieva S, Lamberts SW, Tabarin A, Webb SM, ERCUSYN Study Group. The European Registry on Cushing's syndrome: 2-year experience. Baseline demographic and clinical characteristics. Eur J Endocrinol 2011; 165: 383-392

30 Colao A, De Block C, Gaztambide MS, Kumar S, Seufert J, Casanueva FF. Managing hyperglycemia in patients with Cushing's disease treated with pasireotide: medical expert recommendations. Pituitary 2014; 17: $180-186$

31 Reznik Y,Bertherat J,Borson-Chazot F, Brue T, Chanson P, Cortet-Rudelli C, Delemer B, Tabarin A, Bisot-Locard S, Vergès B. Management of hyperglycaemia in Cushing's disease: experts' proposals on the use of pasireotide. Diabetes Metab 2013; 39: 34-41

32 Kola B, Christ-Crain M, Lolli F, Arnaldi G, Giacchetti G, Boscaro M, Grossman $A B$, Korbonits $M$. Changes in adenosine $5 '$-monophosphateactivated protein kinase as a mechanism of visceral obesity in Cushing's syndrome. J Clin Endocrinol Metab 2008; 93: 4969-4973

33 Fiorentino C, Motta C, Wolosinska DT, Monti S, Mori F, Toscano V. SOM230 in Cushing's disease complicated by poorly controlled diabetes mellitus. J Endocrinol Invest 2011; 34: 731-732 